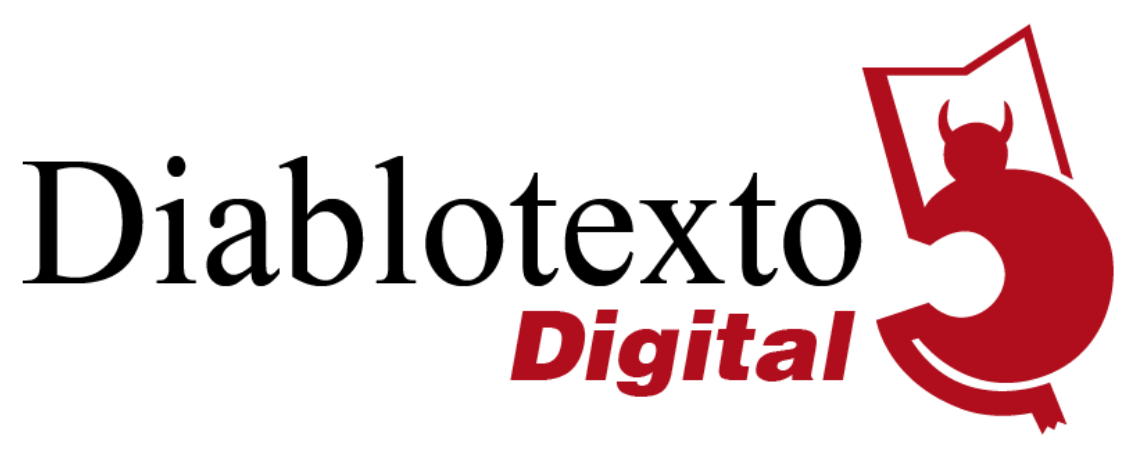

\title{
La experimentación poético-musical en Fábula de Polifemo y Galatea (1698): diálogo aglutinante entre tradición y modernidad ${ }^{*}$
}

The poetic-musical experimentation in Fábula de Polifemo y Galatea (1698): agglutinating dialogue between tradition and modernity

JORDI BERMEJO GREGORIO

UNIVERSITAT DE BARCELONA

Resumen: El estudio pormenorizado de la dimensión poético-musical de Fábula de Polifemo y Galatea (1698), de Antonio de Zamora y Francesco di Russi, revela esta ópera como paradigma inicial de la experimentación de las formas tradicionales hispanas con el lenguaje operístico italiano. En ella se observan piezas herederas de la práctica estrófica calderoniana como soportes textuales de recitativos y arias musicales. Esta apertura poético-musical partirá de la tradición como signo de identidad para engrandecerla a los parámetros culturales europeos, en la que tuvo mucho que ver la reina Mariana de Neoburgo.

Palabras clave: Antonio de Zamora; Francesco di Russi; Ópera barroca; Aria española; Recitativo; formas poético-musicales tradicionales; Calderón de la Barca.

Abstract: The detailed study of Fábula de Polifemo y Galatea (1698), written by Antonio de Zamora and Francesco di Russi, exposes this opera as an initial paradigm of the experimentation of the traditional Hispanic forms with the Italian operatic language. In this play, the Calderonian strophic forms is observed as textual supports of musical recitative and arias. This poetic-musical modernization showed up from tradition as a sign of Spanish identity to enlarge it to European cultural parameters, in which Queen Mariana of Neoburg did much.

Key words: Antonio de Zamora; Francesco di Russi; Baroque opera; Spanish aria; Recitativo; traditionals poetic-musical forms; Calderón de la Barca.

\footnotetext{
* Este trabajo se inscribe dentro del Proyecto de Investigación "Digital Música Poética. Base de datos integrada del teatro clásico español" (FFI2015-65197-C3-2-P), financiado por el Ministerio de Economía y Competitividad e integrado en el Grupo de Investigación Consolidado "Aula Música Poética" (2017 SGR 251), financiado por la Generalitat de Catalunya.
} 
El aperturismo musical que sucedió tras la llegada de Mariana de Neoburgo como reina consorte de España en 1690 aceleró increíblemente la evolución de la música española. Durante el reinado de la última esposa de Carlos II serán Sebastián Durón y Antonio de Literes los que armonizaron la realidad musical española -en la que la palabra ejercía la supremacía (Josa y Lambea, 2012: 151. Stein, 1993: 319)- con el innovador lenguaje musical italiano -y en menor medida el elemento francés (Becker, 1989: 430)- que arrasaba en Europa como símbolo de su época. Antes de la extinción de la casa de Austria, España estaba condenada a unirse a una tendencia musical que la arrinconaba en la esquina de Europa.

Ese proceso inicial se fundamentará en la relación entre las tradicionales hispanas -aquellas que conformaban la convención de Calderón e Hidalgo ${ }^{1}-\mathrm{y}$ las formas italianas en los últimos años del siglo XVII impulsadas por Mariana de Neoburgo. Estos cambios e introducciones adaptadas al marco español serán síntomas inequívocos de, tal como declaró Jesús Pérez Magallón sobre esta etapa, una "conciencia de un país que está viviendo un periodo de crisis: crisis de renovación con anhelo de resurgimiento" (Pérez Magallón, 2002: 68). Por ello, no ha de extrañar que tanto dramaturgos como músicos se preocupasen por participar en un proyecto de creación y modernización de una nueva España en la que la tradición y las innovaciones extranjeras mantengan una relación dialéctica a la par que aglutinante².

Sobre este aspecto entra en juego la relevancia que tuvo la reina Mariana de Neoburgo para "dar paso a un lenguaje diferente que permitirá crear un modelo propio para la representación áulica de la soberana" (Martínez Leiva, 2013: 225). Así pues, la reina se esforzó por aclimatar los estilos musicales a los que estaba acostumbrada en la corte de su Düsseldorf natal (Domínguez, 2009: 208) ${ }^{3}$ y de todo el Imperio, donde el estilo italiano en el teatro musical era

\footnotetext{
1 Es decir, las tonadas a solo mediante la secuencia estribillo-coplas -cuando los dioses cantaban a mortales-, y el romance para los recitativos hispánicos -cuando los dioses cantaban entre ellos, el denominado "lenguaje de los dioses"- (Stein, 1993: 138).

2 Esa relación dialéctica provocará, en palabras de Jesús Pérez Magallón, "un ambiente cultural rico e innovador, en el que la curiosidad por la cultura francesa tiene un papel importante, aunque no exclusivo, y que obviamente no hace desaparecer ni perder significación cuantitativa a quienes permanecen anclados en la tradición, es decir, en la dejación de su autonomía individual ante el poder de la autoridad" (2002: 309).
} 
abrumador ${ }^{4}$. La entrada de piezas, compositores y músicos extranjeros en el reino del último Austria fue por influencia de la reina -directa o indirecta-5, aunque también la nobleza española tuvo un papel preminente ${ }^{6}$. No es casual,

${ }^{3}$ Desde pequeña, Mariana de Neoburgo estaba acostumbrada a divertirse y a entretenerse con música de la moda italiana y con comedias (Solar-Quintes, 1956: 2).

${ }^{4}$ Esto se deduce de las palabras de Bances Candamo sobre los espectáculos en el Imperio: "el señor Emperador tiene para sus festejos quien las escriba en francés y en toscano, de que yo he visto muchas" (Bances Candamo, 1970: 79). Después de la muerte de la emperatriz Margarita Teresa de Austria, "'lo italiano' ganó terreno en la corte de Viena y se colocó en el primer plano en el campo cultural, sobre todo, debido al segundo matrimonio de Leopoldo I con Claudia Felicitas de Tirol, descendiente de los Gonzaga y Medici italianos" (Martínez Tortajada, 2016: 185-186). Además, resultan muy sugerente los envíos entre familiares de ambas coronas desde Viena a Madrid de libretos de óperas italianas, aunque también viceversa con muchas obras de Calderón, como constata Sònia Martínez Tortajada durante los reinados imperiales de Fernando III y de Leopoldo I (Martínez Tortajada, 2016: 173-181).

${ }^{5}$ Una serie de acontecimientos circunscritos a la influencia de Mariana de Neoburgo después de la zarzuela de Durón y Cañizares demuestran la madurez y el convencimiento -tal como lo expresó el propio Carlos II- de los "deseos de comedias armónicas a la usanza de Italia" (Domínguez, 2009: 204) en España: el gusto por los espectáculos musicales de toda la corte hizo que se repusiera la ópera de Calderón e Hidalgo Celos aun del aire matan (1660) el 12 de febrero de 1697; al inicio de ese verano el rey manda orden de traer a Madrid el cantante Matteuccio -que llegaría en noviembre del siguiente- (Domínguez, 2009: 202), al mismo tiempo que la reina hace que se le envíen músicos para la citada Muerte en amor es la ausencia desde Düsseldorf (Baviera Y Maura, 2004: 661 y Ulla Lorenzo, 2010: 150), lugar desde donde ya había hecho traer "piezas musicales de sus compositores favoritos como Johann Paul Agricola, Giovanni Battista Mocchi o Georg Andreas Kraft" (Rodríguez, 2010: 5)-. En las fiestas teatrales ¿Cuál es afecto mayor, lealtad o sangre o amor? -del 17 de febrero de 1697, con texto de Francisco Bances Candamo y músico desconocido- y Destinos vencen finezas -estrenada el 6 de noviembre de 1698, con música de Juan de Navas, texto de Lorenzo de las Llamosas y encargada personalmente por Mariana de Neoburgo (Carreras, 1995: 117)- aparecen instrumentos nada comunes en las orquestas teatrales hispanas de la época como son los oboes, las vihuelas de amor y las de arco "que se iban introduciendo con regularidad en las orquestas a comienzos del siglo XVIII" (Leza, 2004: 53). Los días 27 y 28 de enero de 1698 las compañías de Carlos Vallejo y Juan de Cárdenas estuvieron ensayando "la fiesta de la ópera que se había de representar a sus Majestades" (Archivo de la Villa de Madrid: Secretaría, 2-456-14). También de 1698 está fechada la partitura de la ópera L'Armento de Johan Hugo von Wilderer, que fue enviada por el Elector del Palatinado a su hermana en Madrid, la reina Mariana de Neoburgo (Domínguez, 2009: 208), por lo que "Durón debió de conocer también algunas óperas de Düsserdolf” (Rodríguez, 2010: 5). Al año siguiente, Carlos II mandó al marqués de los Balbases que enviara a Medinaceli lista "de los músicos que el rey desearía fuesen allá [a Madrid] para recitar una ópera que la reina tiene gusto se haga" (Domínguez, 2009: 204). Esta última ópera debía estrenarse en Madrid el 1700 con música de Bernardo Sabadini y con una auténtica orquesta compuesta por músicos napolitanos (Baviera y Maura, 2004: 343), pero el mal estado de salud del rey impidió que finalmente se representara. Así pues, tampoco es casualidad que, a partir de esa época -especialmente a partir del año siguiente- Sebastián Durón iniciase una fase en la que se abrió "a la influencia del dramma per musica, la serenata, el oratorio y la cantata" (Durón, 2016: 26).

${ }^{6}$ Es importante resaltar el papel que tuvieron para la importación del estilo italiano en España el conde de Santisteban -virrey de Sicilia y después de Nápoles-, el duque de Medinaceli -que escribirá, por orden de los reyes, al cardenal Medici para que permitieran al florentino 
pues, que Sebastián Durón fuera nombrado organista de la Capilla Real en 1691 (Martín Moreno, 1976: 145) ${ }^{7}$-un año después de la entrada de la reina-, como que tampoco lo fueran las primeras apariciones de la palabra 'aria' en manuscritos literarios en 1696 con la zarzuela Salir el amor del mundo ${ }^{8}$-con poesía de José de Cañizares y música del mismo Sebastián Durón- y con la fiesta cantada Muerte en amor es la ausencia ${ }^{9}$ de 1697 -con música del mismo compositor y texto de Antonio de Zamora-. Aunque no pueden concebirse los números cantados de estas obras como verdaderas secuencias musicales de recitativo-aria, sí es sintomático la deliberación en la aplicación de la nomenclatura de unas secciones italianas que evidentemente se conocían, así

Matteuccio cantar ante los monarcas españoles-o del marqués de los Balbases -quien será mecenas de Giacomo Facco- (Domínguez, 2009: 201-202). Este último había disfrutado de la ópera Tito Manlio en Venecia el enero de 1697; "later it was his accounts of the different Italian musicians known to him that influenced both his and the queen's desire to see a real Italian opera in Madrid" (Domínguez, 2009: 202). Otros nobles importantes a tener en cuenta como partícipes estimular la música italiana en España fueron el Condestable de Castilla y la condesa de Osuna (Domínguez, 2009: 207).

7 Por su parte, Danièle Becker subrayó que "el elemento musical italianizante empieza a manifestarse a través del virreinato de Nápoles y la embajada en Roma: ingresan cantores napolitanos en la Real Capilla cuya habilidad puede influir en el estilo de Durón y de Literes posteriormente" (Becker, 1989: 431), aquellos en los que los cambios definitorios del nuevo gusto irán más allá de la superficie: "these are internal changes within the music fabric of Duron's Spanish-style pieces. The most audacious sign of the pan-European influence is manifest in his incorporation of arias in da capo form that are written in a decidedly selfconscious Italian style" (Stein, 1993: 330).

${ }^{8}$ En la primera jornada Amor cantará "despacio" una sextilla de versos hexasílabos de rima asonante irregular ("Sosieguen, descansen"), que funcionará como estribillo a tres coplas dodecasílabas -también de rima irregular- y un recitativo en romance. Así se indica en la partitura manuscrita de la obra (Durón, 1696: 17r-18v). No aparece, por lo tanto, la referencia a aria de la sextilla en el testimonio musical, mientras sí que se anotan la nomenclatura de las coplas $(18 \mathrm{r}-19 \mathrm{v})$ y del recitativo $(19 \mathrm{r}-21 \mathrm{r})$. No obstante, sí que se registra como tal en el literario. Dejando de lado la verdadera realidad de la sextilla irregular como aria, es "la primera vez que aparece la palabra area en el manuscrito literario" (Martín Moreno, 1994: 103).

9 En la primera jornada, Júpiter cantará un romancillo ("Las iras detén”) que, como en el anterior caso, hace de estribillo de una larga tonada. De la misma forma, en el testimonio literario de la pieza (Zamora, [1697]: 12v) este número está anotado con la didascalia "Canta aquí aria", pero en la partitura solamente está anotada como "solo" (Durón, h. 1697: 5r). Este número poético-musical se encuentra en Zamora y Durón, 2012: 149-153, vv. 682-761. Para saber más sobre la dimensión musical de esta pieza, véase, del mismo trabajo, las páginas $\mathrm{v}$, xii y xiii, del apartado de la edición musical. 
como el efecto de contraste que se intenta buscar entre las mal denominadas arias y el resto del tono ${ }^{10}$.

A partir de 1697 -o si se quiere a partir del estreno de Salir el amor del mundo- la aceleración para la europeización musical de España siempre tuvo que ver con una reina que supo muy bien utilizar el mecenazgo artístico como arma política para sus intereses particulares ${ }^{11}$. Por ello contó siempre con Sebastián Durón como su compositor español favorito, incluso en el exilio en Bayona tras el estallido de la Guerra de Sucesión en Europa ${ }^{12}$.

Como se ha comentado antes, si bien la nomenclatura 'aria' había aparecido con Salir el amor del mundo (1696) y Muerte en amor es la ausencia (1697), la realidad de las estrofas poético-musicales a las que hacía referencia no era tal. Así que, ante ese ambiente totalmente proclive a la introducción y adaptación del innovador lenguaje operístico italiano, la ópera Fábula de Polifemo y Galatea representa el inicio de la sustitución paulatina pero no homogénea en el teatro musical cortesano "de una estructura musical arraigada en el ubicuo par 'estribillo-coplas' por secciones de recitativo y aria" (Carreras, 2000: 22). Fue el primer ensayo que intentó deliberadamente la escritura poético-musical para números de recitativos y arias. Si bien los recitativos ya se habían utilizado antes con la forma métrica de la silva en pareado, fue aquí la primera vez que formó parte del binomio operístico recitativo-aria, aunque los números de la ópera aparezcan en un primitivo y experimental estado de adaptación hispana.

Así pues, a principios de 1698 aparece Fábula de Polifemo y Galatea. / Dramma per musica, con música de Francesco di Russi y texto del madrileño

\footnotetext{
10 Sobre el número comentado de Muerte en amor es la ausencia, Lola Josa y Mariano Lambea comentarán que hay que destacar "el contraste generado entre el cuatro (“Pescadorcillo...") y el villancico ("Las iras..." / "Por ti...")" (Zamora y Durón, 2012: v).

11 Para este aspecto resulta imprescindible el capítulo "11. Mariana de Neoburgo, las “amables zarzuelas' y la derrota del teatro pedagógico", dentro de Sanz Ayán, 2006: 165-182.

${ }^{12}$ Fuertemente comprometido con el bando austracista en la Guerra de Sucesión -quizás por influencia de Mariana de Neoburgo-, Sebastián Durón fue arrestado en Madrid en agosto de 1706 por celebrar la efímera entrada del archiduque Carlos en la capital. En 1710 se exilió en Bayona, y más tarde en Pau, donde "debió [de] proseguir sus actividades musicales, ya que compuso una comedia que fue representada por los sirvientes de la reina viuda" (Martín Moreno, 1973: 146). Los siguientes años estuvo estrechamente vinculado a Mariana de Neoburgo -formando parte del Consejo de su Majestad y, en 1715, nombrado primer limosnero-, hasta que moriría el 3 de agosto de 1716 en la localidad francesa de Cambo les Bains (Martín Moreno, 1973: 146-148).
} 
Antonio de Zamora; constituido por prólogo y un único acto dividido en seis escenas. Solo nos ha llegado el libreto de esta ópera ${ }^{13}$. La datación de esta pieza es casi segura: la noche del 16 de enero de 1698. Aunque no se indica en el documento, una referencia en La Gaceta de Madrid (martes 21 de enero de 1698: 9-12) concuerda con las circunstancias del estreno14: "el jueves pasado asistieron sus Majestades a la representación de la Comedia de Música que las criadas de la condesa de Lemus repitieron en las casas de Ruy Gómez de Sylva ${ }^{15}$ con notable habilidad y primor" (Gaceta de Madrid, 1698: 12). En efecto, y tal como dice el impreso, la anfitriona y patrocinadora de la fiesta, la condesa de Lemos, instó al dramaturgo a "que hiciese la siguiente fábula, para que cantada junto al clavicordio por algunas señoras sus criadas contribuyese al lícito entretenimiento de una noche" (Zamora, [1698]: 2), por lo que se puede deducir que la iniciativa creadora de la fiesta partió de la condesa. Esta, miembro del círculo próximo a la realeza, debía de conocer la ópera y la música italiana gracias a los conciertos y espectáculos palaciegos de los músicos de la Capilla Real, versados estos en la moda que triunfaba en Europa.

En ese aspecto la autoría de la música de Fábula de Polifemo y Galatea aporta todavía más evidencias de la celeridad que supuso la influencia de Mariana de Neoburgo y lo relevante que fue en el espectáculo privado de la condesa de Lemos. Si bien hay muy pocos datos sobre el compositor Francesco di Russi, su origen italiano es indiscutible. También lo es su relación con la alta nobleza española, tal y como lo demuestra la dedicatoria de la música de Fábula de Polifemo y Galatea a la condesa de Lemos y la cantata a

${ }^{13}$ El título completo es Fábula de Polifemo y Galatea. Por don Antonio de Zamora Oficial de la Secretaría de Indias con la negociación de Nueva España. Puesta en música por el Abate D. Francisco de Russi. Para diversión y festejo de la excelentma. Señora d. Catalina de Silva, y Mendoza, Condesa de Lemos y Andrade, mi señora, [s. I.], [s. n.], [1698]. Solamente se ha conservado un testimonio en la Biblioteca Nacional de España bajo la signatura T/546.

${ }^{14}$ Además, el estatus profesional de Antonio de Zamora a principios de ese año concuerda perfectamente con lo referido en el impreso. El dramaturgo era oficial de la Secretaría de Indias desde el 31 de marzo de 1689 (Martín Martínez, 2003: 24), pero llevaba tiempo intentando ser nombrado gentilhombre, cargo que juró, precisamente, el 30 de junio de 1698 (Martín Martínez, 2003: 45). Debido a lo relevante del título, hubiera sido impensable que no se mencionara en el impreso y solo el de oficial de la Secretaría de Indias. Por lo tanto, hubo de publicarse Fábula de Polifemo y Galatea entre enero y junio de 1698.

${ }^{15}$ Ruy Gómez de Sylva hace referencia al Príncipe de Éboli (1516-1573), duque de Pastrana y favorito de Felipe II. En las circunstancias históricas de la Fábula de Polifemo y Galatea, el duque de Pastrana era Juan de Dios Silva y Haro (1672-1737). 
solo "Lunga stagione dolente" que se encuentra en un manuscrito titulado Arie italiane di diversi autori escogidas para la Exma. A. Duquesa de Osuna ${ }^{16}$. Tal debió de ser el agrado de la reina con este músico que más tarde formaría parte -también- de la Capilla Real de Mariana de Neoburgo en su exilio en Bayona ${ }^{17}$, como se señala en la "Relación de criados de los años 1701-1740" (Solar-Quintos, 1956: 168). Que sea la tan temprana fecha de 1698 la primera en la que aparece el nombre del compositor italiano en España revela que muy posiblemente fuera traído ex profeso por la condesa de Lemos para que compusiera la música de una pequeña ópera que impresionara a los reyes. $E$ hizo lo propio -en la dimensión poético-musical- con Antonio de Zamora. Ante la relevancia que, como demostraremos, tendrá esta pieza, la aristócrata no dudó en utilizar el poder de la ostentación musical de una obra donde se intenta recrear el sistema operístico italiano - del gusto de la reina- con el fin de agradar a los reyes y asegurarse una buena posición para ella y los suyos en el tormentoso escenario político de los últimos años de Carlos II.

El texto de lo que fue el espectáculo, completamente cantado como indica el subtítulo, se inicia con una Introducción música a la fábula escénica de cinco voces $^{18}$. Esta pieza efímera continúa la tradición palaciega española de la loa como anunciante de la ocasión del espectáculo -el Carnaval-, pero, por su configuración completamente cantada, con música, y la nomenclatura utilizada rememora los prologues de las tragédies en musique de Quinault y Lully, y, por supuesto, los prólogos de las óperas venecianas. De extensión muy breve (setenta y siete versos), combina un estribillo de métrica irregular de rima asonantada en los pares (seis y diez sílabas) con cuatro coplas irregulares de pie quebrado (formadas por heptasílabos, octosílabos, dodecasílabos y hexasílabos), una silva en pareado y cinco redondillas. Pero es el texto de la fábula puesta en música propiamente dicha en un único acto y con seis

\footnotetext{
${ }^{16}$ La cantata se encuentra en Russi, h. 1706: 63r-66v. A propósito de la casa de Osuna y la música italiana, se tiene constancia que, al menos desde 1712, el duque protegió a Sebastián Durón en Pau con el pago de una pensión (Martín Moreno, 1973: 146).

17 Gloria Martínez Leiva hizo énfasis en el gusto de la reina viuda por la música: "dispondrá de una orquesta de unas diez personas de músicos de cámara, que amenizaban su tranquila vida. Mariana sentirá siempre una especial predilección por la música. En Bayona donde tendrá más tiempo de ocio, su amor y dedicación a esta aumentará" (Martínez Leiva, 2013: 229).

18 La Introducción música a la fábula escénica de cinco voces Polifemo y Galatea se encuadra en Zamora, [1698]: IX-XI.
} 
escenas explícitamente indicadas -el primer testimonio del siglo XVII, de hecho $^{19}$ - el que revela la importancia que toda la ópera tiene en la comprensión de la adaptación hispana del nuevo lenguaje poético-musical. En ella aparecen formas tradicionales, de experimentación y propias del lenguaje operístico. De este modo se inicia la ópera:

[E]SCENA PRIMERA

Polifemo y Galatea

EL CORO

Pastores a la ribera, a la espesura, zagales, al viento y al campo vibren en seguimiento de Acis la libre traílla, la dócil pigüela, la turba veloz de ventores y sacres, $y$ en ecos iguales

Polifemo solo se oiga decir "ial monte, al valle!"

Fugitiva hermosura, en quien por hermosura y fugitiva hoy dos voces siguió mi planta altiva el norte material de sus venturas.

Por más que el ceño dura de tu desdén tirano excusarte es en vano, pues tu esquivez adoro a que escuches la voz con que hablo y lloro.

Galatea celestial, oye mi mal, y aunque lo sienta el rigor, mira mi amor,

pues no puede mi fineza vivir sin que tu belleza la dispense algún favor. ¡Oye mi mal, mira mi amor! (Zamora, [1698]: 1-2)

El comienzo con el coro no varía mucho respecto a los comienzos con el cuatro de fiestas anteriores de la última década del siglo ${ }^{20}$. Pero $-y$ es aquí la novedad- después el primer personaje que aparece -Polifemo- empieza su actuación con la clara estrofa del recitativo -que en este caso se inicia con un

\footnotetext{
${ }^{19}$ Muy al contrario que en las publicaciones de teatro -incluidas las fiestas reales anteriores-, es la primera vez que en fecha tan temprana como 1698 se divide la pieza en escenas. La influencia de las publicaciones operísticas tanto francesas como italianas anteriores es total, lo que deja entrever mucho lo que se deparará -y deparó- el dramma per musica en España. Le seguirá la Ópera escénica deducida de la guerra de los gigantes (1701), creada por Durón y poeta desconocido para la boda del conde de Salvatierra, el 23 de febrero de 1702. Es muy sugerente que la partitura de esta pieza, como la Fábula de Polifemo y Galatea, está constituida mediante una "Introducción" y un acto único dividido en "seis 'escenas' que están explícitamente nombradas y numeradas en la partitura" (Durón, 2017: 32).

${ }^{20}$ Como en otras ocasiones, el coro volverá a aparecer para cerrar cantando un diálogo o una escena, preparando el escenario para la concatenación de la siguiente -con el sintagma tópico de "al monte, al valle"- (Flórez Asensio, 2006: 35).
} 
madrigal- con la que presenta los motivos que lo condenan y que vertebrarán la trama mitológica conocida por todo el público: el amor hacia Galatea y el rechazo de esta. Seguidamente, como es propio después del recitativo, se pasa al lamento del que canta en forma lírica y condensada con lo que parece un aria compuesta por dos estrofas de métrica menor. Estamos ante la escena dramática idónea para la recreación poético-musical propia del lenguaje operístico: si después de un recitativo -en el que el personaje expone narrativa o descriptivamente las inquietudes o asuntos que le afectaban a nivel subjetivo- el personaje se sobresalta y se abstrae suspendida y líricamente por estímulo del exterior o por recapacitación de lo que le ha pasado (Hill, 2010: 213-214) -como le ocurre a Polifemo-, es necesario que la música reproduzca un cambio repentino del aire, del mismo modo que la estrofa del recitativo dé paso rápidamente a un verso corto, ágil y agudo: las arias. La partición del número musical en dos secciones bien diferenciadas-cuando antes ese número estaba formado únicamente por la silva en pareados- y el cambio de registro poético de narrativo a lírico evidencia que estamos ante el mismo fenómeno de recategorización del recitativo y aparición de las arias que más de medio siglo antes había ocurrido en Italia ${ }^{21}$. Por lo tanto, y a pesar de que no se conserva la partitura de la ópera, el efecto contrastivo poético entre las secciones del número hubo de tener su reproducción en la dimensión musical; ambas son, al fin y al cabo, la recreación musical y poética de un tratamiento dramático con nuevo objetivo: reflejar perfectamente en la escena las modulaciones de los afectos, estados y sentimientos que el desarrollo de las acciones produce en la psicología lírica de los personajes. El ineludible contraste en esa evolución responde, pues, a que un sentimiento, una sensación, no existe sin la experimentación de su opósito.

En la misma opera Zamora escribe otras estrofas como aria que, a simple vista, coinciden mucho más con el modelo poético-musical italiano. En el final

21 El antiguo recitativo hispánico en silva en pareados desaparecerá y la forma métrica se utilizará ahora únicamente para hacer avanzar la historia a través de la palabra narrativa y descriptiva de las acciones -recitativo secco, sin apenas expresión subjetiva-, antes de que el aria suspenda momentáneamente el desarrollo de la trama. En consecuencia, los recitativos se realizarán como recitados en monodia con pocas inflexiones y con un escueto acompañamiento instrumental (secco) y prepararán el terreno para la explosión lírica y melodiosa de las arias (Hill, 2010: 220). 
de la escena segunda, tras un recitativo en diálogo entre Acis y el gracioso Dorisco en el que hablan de la salida de Galatea -compuesto por una silva en pareados de veintitrés versos-, Acis, solo en escena, se abstrae de la acción y empieza el canto lírico y concentrado de sus sentimientos:

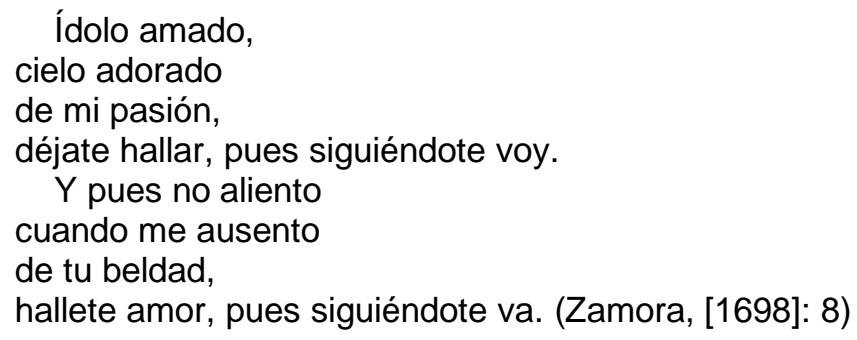

Como se ve, en estas estrofas hay una leve variación con respecto a las primeras antes expuestas. La diferencia está en las variantes con que Zamora imprimió un mismo recurso: la estructura paralelística de los últimos versos de estrofa. Mientras que en el último verso de "Galatea celestial" la reminiscencia y repetición se hace con fragmentos de la primera estrofa -una clara influencia de los coros y estribillos anteriores-, en "Ídolo amado" se construye por el paralelismo sintáctico de los últimos versos de ambas estrofas. Esta última se asemeja mucho más al canon poético-musical operístico sobre el que el propio Russi compuso la primera aria de la cantata a solo "Lunga stagione dolente" antes comentada, de autoría textual desconocida:

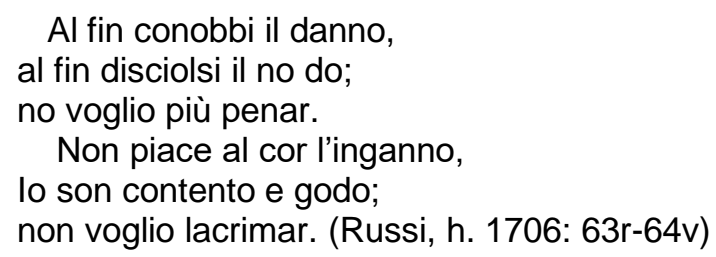

Véase el paralelismo de los últimos versos de ambas estrofas, análogas a las de la música de Russi y de su rima aguda -rima que con el tiempo se volverá en canónica en las arias da capo-, y atiéndase la naturaleza lírica y expresiva de las letras.

Apreciaciones aparte, se ve que tanto en "Galatea celestial" como en "Ídolo amado" el requerimiento de correlación se cumple o, al menos -pero lo más importante-, las estructuras poético-musicales que escribió Zamora podían emplearse perfectamente como sustancia lingüística que se asiera a la música "a la usanza de Italia" de Russi. No obstante, la estructura paralelística de las 
estrofas con la que se quiere conseguir el efecto de analogía que se producen en ambos números no es una imitación exacta de las arias da capo italianas ${ }^{22}$. En realidad es una adaptación hispánica sui generis de letra para música italiana, característica del periodo de transición y experimentación en el que la música cortesana se encontraba a finales del reinado de Carlos II y Mariana de Neoburgo.

La cuestión que las dos letras de la ópera plantean -más allá de lo que la tipografía evidencia- es si Zamora sabía la trascendencia de la pieza que estaba creando y cómo haría para que la letra encajara en el esquema bimembre específico de recitativo y aria que la música exigía.

El primer indicio serio para afirmar lo dicho es, precisamente, el subtítulo italiano de la obra: dramma per musica, la primera, de hecho ${ }^{23}$. La anotación literal de la denominación indica que Zamora era consciente de que estaba recreando -al menos lo intentaba poéticamente como cuerpo para la músicael espectáculo italiano por antonomasia ${ }^{24}$. Entonces, Zamora sabe de la estructura bimembre del recitativo y aria del lenguaje estrófico operístico; y lo plasma con una clara diferenciación entre la silva primero y las dos coplas breves después. Se da cuenta de que la autonomía estrófica de la primera en el lenguaje operístico italiano es aproximada a la española en la construcción de las tonadas a solo en romance o en la misma silva en pareado. El problema, o la dificultad, estaba en las dos estrofas del aria y la transición contrastiva

${ }^{22}$ Por su parte, Raúl Angulo y Antoni Pons, no creen que La Fábula de Polifemo y Galatea contenga arias da capo (Durón, 2015: 22). El análisis que pretendemos realizar intentará arrojar luz sobre la realidad operística o no de este tipo de estrofas en la pieza de Zamora.

${ }^{23}$ La siguiente será, precisamente, la pieza denominada expresamente Ópera escénica deducida de la guerra de los gigantes (h. 1701), de Durón y de poeta desconocido. Tal como comentan Raúl Angulo y Antoni Pons, "es posible que este principio estructural, que rompía con la tradición del teatro cortesano, sea una de las razones por las que se aplicó el adjetivo 'escénica' al sustantivo 'ópera' en la portada de la partitura” (DURÓN, 2017: 32). Como antes se ha dicho, esta ópera de Durón tendrá muchas similitudes -sino influencias- con la Fábula de Polifemo y Galatea.

${ }^{24}$ Resulta muy indicativo de los incipientes intentos de introducción de las secciones italianas en el contexto español las referencias expresas de la nacionalidad de estas innovaciones. Como en el dramma per musica de Zamora y Russi, ocurre lo mismo en la Capilla Real de principios del siglo XVIII: "en la mayoría de los ejemplos más tempranos, las secciones foráneas eran introducidas en los villancicos por personajes extranjeros que cantaban al estilo de su país. [...] Uno de estos primeros ejemplares aparece en el cuarto villancico de Reyes de 1703, que presentaba un personaje italiano cantando 'al uso de Italia'. La estructura básica de la pieza se componía de tres secciones, introducción, estribillos y canción. En mitad del estribillo el personaje se presenta al público cantando un recitado y una arieta, mientras que la canción se divide en nueve secciones" (Torrente, 2000: 89). 
poético-musical desde un recitativo secco. En las ocasiones anteriores de zarzuelas del siglo XVII cuando una tonada a solo se cerraba con una especie de coda compuesta por otra estrofa, el contraste estrófico y métrico era muy leve ${ }^{25}$-se mantiene el mismo tipo de rima, las más de las veces son variantes hexasilábicas del romance-, y sin apenas variación del lenguaje poético más que a modo de conclusión conceptual -que no expresión lírica- de lo antes cantado $^{26}$. Por lo tanto, Zamora debía buscar otros recursos que dominase para la escritura satisfactoria de las estrofas del aria.

Para ello, como en otros muchos aspectos, Zamora -y más tarde Cañizares- partieron de Calderón con el fin de adaptar y renovar por exigencia de la moda musical imperante. Y en 1698 la tendencia italiana se imponía por los gustos musicales -no tanto poéticos-de Mariana de Neoburgo, que la nobleza quería satisfacer y debía imitar para prosperar en la corte. Dámaso Alonso ya subrayó la construcción correlativa de los autos sacramentales y las comedias mitológicas, especialmente en los menos realistas 0 más conceptuales: "en ellos hay un constante cambio entre la progresión plurimembre correlativa y la progresión monomembre" (2000: 339). Los dos géneros con más dimensión poético-musical del teatro español del siglo XVII estaban formados mediante un dinamismo tanto poético y musical como dramático y escénico basado en la reiteración de estructuras paralelísticas coplas-estribillos que se van repitiendo de muy variadas maneras- (Alonso, 2000: 340). Si bien en Calderón y muchos otros existen ejemplos de tonadas a solo que se cierran con un cambio estrófico por medio de una copla, hay a veces en que no es un segmento poético-musical autónomo el que cierra el número y lo sintetiza, sino un estribillo que había aparecido antes,

${ }^{25}$ La disparidad métrica tan pronunciada en un mismo tono no era propia del uso español tradicional. Pablo Nasarre, en su fundamental Escuela música según la práctica moderna (1683-1723/1724), reconoce la tendencia a la acentuación de los contrastes en los movimientos de la música instrumental italiana, y matiza que "esta moda de música han tomado los músicos españoles de músicas extranjeras como italianas y otras. El aire propio de España es pasar de la música pausada a la veloz, no de pronto, sino es por sus grados" (Nasarre, 1724: 443).

${ }^{26}$ Este es el caso, entre otros muchos, de las cuatro tiradas que el personaje alegórico de la Fama canta en Hado y divisa de Leonido y Marfisa (1680), última fiesta real de Calderón de la Barca. El personaje repetirá cuatro veces la misma estructura estrófica: un romance con una copla hexasilábica (romancillo) como coda, y cuyos últimos dos versos se repiten. Reproducimos la primera: "volando veloz / da el Aura sutil, / el ala la pluma / y el bronce el clarín" (Calderón de la Barca, 1973: 2142). 
habitualmente un coro o viceversa ${ }^{27}$. Este elemento será el que pondrá las bases para la solución del problema del aria. El efecto de repetición del estribillo a modo de coda de una intervención cantada consigue un leve contraste poético-musical ${ }^{28}$. En este caso -y en los de la intervención del coroel dramaturgo aprovecha la reiteración del estribillo como punto álgido de la expresión subjetiva del personaje ${ }^{29}$, algo que está en la esencia también de los números del aria da capo.

Estas tonadas con forma cíclica en la que una serie de coplas se alternan con un estribillo son, según María Asunción Flórez, los exponentes poéticomusicales más dinámicos del teatro musical del siglo XVII, tanto en el nivel propiamente dramático como musical, además de ser considerados por Hidalgo y Calderón parte importante para la unión entre las escenas (Flórez Asensio, 2006: 318) -junto con las mutaciones espectaculares-:

Aunque no se haya conservado la música me parece evidente que el texto refleja un contraste -estilístico más que métrico- entre copla y el estribillo, que pudo ser reflejado musicalmente por un cambio de compás, con lo que tendríamos aquí un ejemplo del contraste rítmico binario (copla) - ternario (estribillo) que caracteriza a muchos tonos, teatrales o no (Flórez Asensio, 2006: 247).

En efecto, ese contraste binario-ternario podría ser semejante al que debía existir entre recitativo y aria da capo en el lenguaje operístico italiano ${ }^{30}$. Es

${ }^{27}$ Es el caso, por ejemplo en La fiera, la piedra y el rayo (1652), del número cantado y escenográfico de Anteros, construido por un tono que abre y cierra un romance por una copla romancillo ("Ama, amada Anajarte") en función de estribillo (Calderón de la Barca, 2000: 522, vv. 2701-2728).

${ }^{28}$ Otro ejemplo muy certero lo encontramos en la ópera de Calderón Celos aun del aire matan (1660). Al inicio de la primera jornada, la ninfa Procis, sacerdotisa de Diana, trae presa con un coro de ninfas a la también sacerdotisa Aura. Su intención es darle muerte como castigo por haber sido sorprendida en amores con el pastor Eróstrato. La rea, cuyas primeras intervenciones se limitan a repetir el estribillo " $i A y$, infeliz de aquella / que hizo verdad haber quien de amor muera!' es atada a un árbol y suplica cantando un romance que finaliza con el mismo estribillo (1959: 2220).

29 Según María Asunción Flórez, los estribillos del coro, "debido al fuerte componente psicológico de la mayoría de ellos, se convierten en el vehículo perfecto para que los personajes exterioricen sus sentimientos, cumpliendo con la teoría de los affeti' (2006: 320).

${ }^{30}$ Lógicamente, esto no quiere decir que el modelo estrófico de los recitativos españoles "ariosos"-sean como los italianos. En el español, "aunque el bajo es melódicamente estático y rítmicamente inactivo, y la parte vocal incluye una gran cantidad de repetición monótona de notas, como en el recitativo italiano, los ritmos son esquemáticos y repetitivos, sin intentar imitar el lenguaje natural, un objetivo del recitativo italiano. Los modelos y las fuentes para este estilo de recitación se encuentran en las cuartetas de los romances españoles y no en la ópera o la monodia italiana" (Hill, 2010: 287). La estructura estrófica de estas tonadas con repetición de melodía fueron vistas por el anónimo autor de /l Corago como muy válidas entre otras tonadas nacionales para dar variedad y gracia las piezas musicales: "l'arie napolitane, le 
importante anotar que ese contraste tanto de las coplas que se repiten en el primer caso como de las estancias de las arias habitualmente están formadas en el modelo ternario ${ }^{31}$. Entonces, y ya en el plano textual, lo que se buscaba para 1698 podía basarse en un recurso propio de la tradición hispánica. Esta patente estructura paralelística común en las fiestas reales de Calderón y sus seguidores es lo más próximo al requerimiento de expresión lírica de las pasiones de la solista, con un cierto contraste -al menos musical- y efecto reiterativo propio del lenguaje del aria da capo; son rasgos que ambas tradiciones poéticas compartían en la mayor parte del siglo XVII ${ }^{32}$, pero que la exigencia musical de la modernidad de finales del siglo hace que se adapte la dimensión española a los parámetros de la italiana.

No se puede olvidar que la principal meta de la Fábula de Polifemo y Galatea era la representación o acercamiento de una ópera italiana moderna. $\mathrm{Y}$, en ella -tal y como constataron los deseos de los reyes sobre la venida de músicos italianos, que no de dramaturgos- el elemento indispensable y que regía el espectáculo en casa de la condesa de Lemos era el musical, no tanto el teatral o el poético y métrico. Vuélvase a tener en cuenta la autoría italiana de la partitura y el vínculo que con Mariana de Neoburgo tendría Francesco di Russi. Los textos de Zamora otorgan claros indicios de que, a nivel musical, el compás ternario de la aria da capo podía cumplirse, aunque en el plano estrófico no coincidiera canónicamente con los modelos italianos. Era una

franzese, le siziliane, le spagnole e simili hanno tutte la sua propia voce e vaghezza" (citado por Flórez Asunción, 2006: 35)

31 Jack Sage explicó breve y brillantemente este paralelismo contrastivo musical del siglo XVII: "al mediar el siglo XVII vemos que el contraste entre las dos secciones empieza a cristalizarse, de forma que la copla en metro $\varnothing$ va aproximándose al estilo expresivo recitativo 0 rappresentativo, y el estribillo en metro ternario conserva la tendencia melódica" (1970: 182).

32 En el caso español, Sage explica que "dicho contraste podría explicarse, claro está, como una consecuencia del villancico [...], con sus raíces en el zéjel [...]. Pero tampoco hay que perder de vista el hecho de que la boga del estribillo (o el estrivo o la vuelta o la seguidilla o el retruécano), no es, ni mucho menos, peculiar a España, como tampoco lo fue la forma del villancico: coincide con el "burden" en Inglaterra, por ejemplo; y el contraste entre el metro C y metro ternario coincide con el desarrollo operístico del recitado más aria (o arioso) en Italia" (1970: 182). 
solución, digamos, al hispánico modo que aparecerá varias veces más en el texto ${ }^{33}$.

Así pues, ante el desafío que suponía el encargo de un dramma per musica para la condesa de Lemos -y los reyes-, es más que probable que Zamora recurriera tanto a las óperas y zarzuelas de Calderón como al consejo del propio Russi. Para conseguir la recreación total del contraste tanto rítmico y melódico como del lenguaje descriptivo al lírico, el madrileño adaptó al modelo de las estancias del aria mediante la síntesis de los recursos poético-musicales que la tradición anterior tenía más próximos a ese objetivo. Podía haber seguido la estructura italiana de dos estrofas distintas -y que en la partitura se repitiera la primera con alguna variación-, pero no lo hizo, a pesar de la formación operística del compositor ${ }^{34}$. Debido al peso de la tradición dramática calderoniana y simbólica española de esta -además de la no referencia de libreto operístico italiano por parte del impreso-, creía que adaptando en estrofas independientes ese recurso poético-musical del estribillo al carácter subjetivo y lírico daría el resultado esperado de repetición del primer miembro para arias musicalmente italianas. Podemos decir, pues, que Zamora hizo este proceso de oídas: construcción de las estrofas basada en los parámetros y necesidades musicales. Entonces, en España el lenguaje poético-musical operístico se importó a través de la música antes de la llegada de los Borbones ${ }^{35}$.

\footnotetext{
${ }^{33}$ Volverá Polifemo a cantar tras un recitativo en silvas unas estrofas similares a la primera en dos ocasiones: "Teman, teman los riscos" (Zamora, [1698]: 10) y "Espera, traidor" (Zamora, [1698]: 21). Lo mismo hará Acis al final de la pieza con "Advierte mi dueño" (Zamora, [1698]: 22).

${ }^{34}$ Por lo que se está diciendo hasta aquí, parece evidente que las influencias italianizantes en el apartado poético-musical para Zamora vinieron únicamente desde la dimensión musical, no propiamente métrica, estrófica o dramatúrgica. A pesar de haber constancia de libretos traducidos al español de óperas italianas representadas en las Viena (Martínez Tortajada, 2016: 181), en las cortes virreinales -o incluso de óperas con texto en español y música italiana, como son los casos de El templo de Palas (1675) y de El robo de Proserpina y sentencia de Júpiter (1679), ambas estrenadas en el Palacio Real de Nápoles (Cotarelo Y Mori, 1911: 23) - y que el flujo de personal institucional de vuelta a la península lbérica era consecutivo -se renovaba cada cinco años (Cotarelo Y Mori, 1911: 22)-, no parece que en Madrid se tuvieran en consideración como base a nueva creación de zarzuelas y óperas hispanas.

${ }^{35}$ El caso de esta opereta de 1698 que estamos tratando parece aportar pruebas que confirman el mismo proceso que ocurriría más adelante: "aparentemente, Goldoni fue importado en España de la misma manera que Metastasio, es decir, a través de la música" (Kleinertz, 1996: 10).
} 
Entonces, y teniendo muy en cuenta la naturaleza interartística y de reciprocidad entre poesía y música en el género de la ópera, si tanto "Galatea celestial" como "Ídolo amado" de Fábula de Polifemo y Galatea son parecidas y cumplen a grandes rasgos los mismos parámetros estróficos, métricos y temáticos que aquellas que se encuentran de Russi en Arie italiane di diversi autori escogidas para la Excma. A. Duquesa de Osuna, ¿no habría de considerarse arias los dos textos de Zamora, a pesar de que no se haya conservado la partitura de 1698? Aunque estén configuradas desde la tradición poético-musical calderoniana y el primero no siga ortodoxamente el modelo estrófico de las estancias italianas coetáneas, realizan perfectamente la función tanto poético-musical de soporte textual de un estilo de música ya definido como lírico y expresivo -dramático-de las arias de las óperas italianas -que el compositor conocía-. Estos dos ejemplos, por lo tanto, consiguen a nivel práctico lo que demandaba la dimensión poético-musical italiana en la ópera a partir de Cavalli: son escenas articuladas por la sucesión de recitativos vehículos musicales del texto y la acción- y $\operatorname{arias}^{36}$.

Estas son las innovaciones en el plano poético-musical que se documentan al menos desde 1698. Pero el texto de Zamora está lejos de gozar de una cohesión de sucesiones de recitativo-aria. La diversidad y naturaleza híbrida es el principal rasgo que define tanto esta pequeña ópera como la época de experimentación hacia la modernidad a la que responde. Los romances, seguidillas arromanzadas y las redondillas -con o sin estribillo- se combinarán y se mezclarán con coplas irregulares asonantadas en los pares con estribillos parecidos. Como era de esperar, en Fábula de Polifemo y Galatea hay muchos testimonios de modelos poético-musicales utilizados y asentados por Calderón e Hidalgo, tanto en los coros como en algunas tonadas a solo ${ }^{37}$. Parece haber

\footnotetext{
${ }^{36}$ Sobre la primera aria "Ídolo amado", Raúl Angulo y Antoni Pons arguyeron para demostrar que Fábula de Polifemo y Galatea no contenían arias en que "Zamora evita la estructura en dos estrofas que es característica del aria italiana, escribiendo tan solo una estrofa y repitiendo al final el primer verso, repetición que sirve de Da capo. La razón de tales anomalías quizá se deba a que en estos años Zamora, no familiarizado o no del todo conforme con las convenciones del dramma per musica, veía absurda por inverosímil la repetición íntegra de toda una estrofa por parte de un mismo personaje" (Durón, 2015: 22). Como se va viendo, estas palabras quedan plenamente cuestionadas.

${ }_{37}$ Un ejemplo es un largo romance acabado con dos coplas hexasilábica (romancillo) en forma de coda que canta Acis en la escena cuarta cuando empieza a temer a los celos de Polifemo:
} 
una tendencia más o menos numerosa de formar estrofas métricas tradicionales acabadas con versificación propia del recitativo -quizás para ayudar a las criadas españolas de la condesa de Lemos que cantaron al clavicordio, responsable del bajo continuo del recitativo- ${ }^{38}$.

La condición de ensayo general de puertas adentro de Fábula de Polifemo y Galatea facilitó la realización de una opereta que intentara reproducir la dinámica operística moderna, de novedoso entretenimiento musical y solaz de reyes, que, si bien no sentaría cátedra inmediatamente, sí mostraba el conocimiento, la actitud y la aptitud española para la escritura de libretos de ópera. Por ello no extraña que en unas de las últimas fiestas reales oficiales a las que asistió Carlos II, Destinos vencen finezas (6 de noviembre de 1698) con texto de Lorenzo de las Llamosas y música de Juan de Navas- y Siempre hay que envidiar amando (21 de julio de 1700) -del propio Zamora y músico desconocido-, si bien con partes musicadas y cantadas -especialmente la primera-, no aparezcan número alguno de recitativo-aria como en la pequeña ópera de Zamora ${ }^{39}$. La autocelebración oficial de estos espectáculos áulicos -y

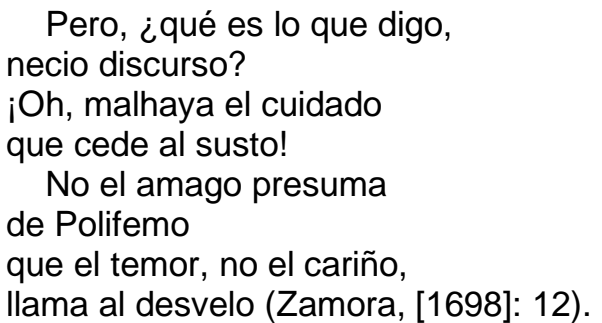

Véase la semejanza con las intervenciones cantadas de la Fama en Hado y divisa de Leonido y Marfisa de Calderón, que se ha mostrado más arriba.

${ }^{38}$ Es el caso, por ejemplo, de coplas heptasilábicas en asonancia en los pares con estribillos compuestos por un heptasílabo y un endecasílabo. Al inicio de la escena cuarta, de lo que parecen ser tres tonadas de la que reproducimos la primera estrofa y el correspondiente estribillo:

AcIS

¿Adónde, hermoso dueño,

a mi pasión te ocultas,

sin ver que sin tu vista

no puede haber fortuna?

¡Pero, ay estrella injusta,

que todo es pena donde todo es duda! (Zamora, [1698]: 11)

${ }^{39}$ A propósito de la música de Destinos vencen finezas, si bien hubo innovaciones en cuanto a instrumentos nuevos -introducción de oboes, vihuelas de amor y de arco-, en general se basaba en la "tipología formales ya conocidos: estructuras estróficas con estribillo, como la tonada o los coros (con estrofa a solo), y el recitado, principalmente. Estos cambios en el gusto 
la seguridad de éxito del gusto mayoritario o incluso popular de las formas hispanas (Leza, 2004: 58)- exigía que se respetara la línea creada por Calderón como representatividad de los Austrias. Incluso ocurriría lo mismo en la primera ópera y pieza teatral que viera el nuevo rey, Felipe V: Quinto elemento es amor, ópera hispana de Antonio de Zamora y Sebastián Durón, se representó ante el rey Borbón el 1 de mayo de 1701 -día de San Felipe(Bermejo Gregorio, 2017: 91). La pieza, construida siguiendo la métrica y los patrones de la dramaturgia poético-musical calderoniana, fue configurada como emblema de la España de Felipe $\mathrm{V}$ ideada por españoles desde los últimos días de Carlos II, lo que hizo que fracasara estrepitosamente ${ }^{40}$. No sería hasta a partir de Hasta lo insensible adora (17 de septiembre de 1704) que las formas castellanas empezarían a perder el protagonismo estrófico a favor de la introducción cada vez más asidua y más aproximada a las secuencias de recitativos y arias eminentemente musicales ${ }^{41}$.

Como se va viendo, la convivencia y mezcla entre todas las formas comentadas aquí marcarán la paulatina formación de la nueva realidad poéticomusical en España del siglo XVIII. Ese proceso, siguiendo lo dicho por Rainer Kleinertz, nunca será cohesionado ni en el campo estrófico, ni métrico ni mucho menos en el de la dramaturgia (1996: 120-121). La viveza de las formas estróficas y métricas tradicionales será también sintomática de la pervivencia dramatúrgica del teatro del XVII en las fiestas reales de principios del siguiente.

[los instrumentos] no influyeron por lo que vemos ni en las formas musicales empleadas, que siguen siendo las tradicionales, ni en la concepción del propio espectáculo dramático" (Carreras, 1996: 126).

${ }^{40}$ Esta ópera se ha estudiado detenidamente en Bermejo Gregorio, 2017.

${ }^{41}$ En Hasta lo insensible adora destacan las "arias da capo, la utilización de los instrumentos de un modo idiomático, el uso de compases de tipo ortocrónico y, por último, la presencia de tonalidades con dos sostenidos y dos bemoles en la armadura" (Durón y Navas, 2017: 32). A partir de entonces, el lenguaje operístico estará presente en cada vez más en las fiestas reales que se estrenasen a partir de 1705, tales como como Apolo y Dafne (h. 1705), Veneno es de amor la envidia (1706), Todo lo vence el amor (1707), Decio y Eraclea (1708), una "ópera para recitar en música, según el estilo y metro italiano» (Durón, 2015: 9), Acis y Galatea (1708), Nuevas armas de amor (1711), la Fábula de Acis y Galatea (1711), entre otras muchas encargadas y representadas para ocasiones privadas de la nobleza, como fue la comentada Ópera escénica deducida de la guerra de los gigantes (h. 1701). 
El gran cambio que intentamos testimoniar con Fábula de Polifemo y Galatea se produjo solamente a nivel poético-musical. Vistas en la estructura global de la pieza, las fiestas reales de entre siglos continuarán la dramaturgia barroca calderoniana y solamente guardan semejanza formal, métrica y, en menor medida, temática con la ópera seria italiana ${ }^{42}$.

El hibridismo poético que se probó en Fábula de Polifemo y Galatea se convertiría rápidamente en la tónica general al entrar el nuevo siglo ${ }^{43}$. Los números musicales de las próximas fiestas reales -estrenadas desde comienzos del siglo para ocasiones oficiales- estarán construidos mediante una alternancia de viejas y nuevas estructuras, pura dialéctica inclusiva y aglutinante entre la tradición y la modernidad. Esta tendencia a combinar secciones tradicionales con italianizantes -o italianizadas- se producirá también en las composiciones sacras y profanas de la Capilla Real, especialmente durante el tiempo en que Durón fue maestro (1701-1706) $)^{44}$. Por ende, esta incipiente etapa deja entrever las enormes inquietudes y el ambiente intelectual y creador que había en España, con lo que se rompe el perjuicio de decadencia, estancamiento y agotamiento de la época de entre siglos.

$42 \mathrm{La}$ indispensable aparición de los graciosos -reivindicando ahora que "no todo en las zarzuelas / se lo han de cantar los dioses" (citado desde Cañizares, 2011: 58-59), como lo hace el gracioso Sátiro de Cañizares en Montes afirma el desdén (1697), o el mismo Dorisco en Fábula de Polifemo y Galatea-, así como la simbología cosmológica barroca, las acciones complejas y enredadas y la inexistencia en la estructuración de la comedia nueva española de una misma acción en distintas y delimitadas escenas o módulos -propias de la dramaturgia operística italiana- seguirán vigentes en el siglo XVIII. Para un mayor conocimiento de estos aspectos en las zarzuelas y óperas representadas en Madrid en la década de 1720, véase Carreras, 1996.

${ }^{43}$ Este aspecto definiría la música teatral de entre siglos, tal como subraya José Máximo Leza: "la paulatina sustitución de formas estróficas por arias de claro origen italiano es el reflejo de un contexto musical cambiante en el que la compleja introducción de la ópera italiana en España iba transformando con mayor rapidez determinadas formas musicales que las estructuras dramatúrgicas del teatro musical hispano en las que se insertaban" (2004: 75-76).

${ }^{44}$ Álvaro Torrente estudió la introducción y el asentamiento del recitado y las arietas en los villancicos de la Capilla Real entre 1700 y 1740 (2000). Exactamente igual que pasaría en la música teatral, "durante los años 1701-1709 las secciones modernas se introdujeron de forma lenta y gradual. En principio esto no significó una sustitución de elementos tradicionales, cuyo número comenzó a disminuir gradualmente, sino más bien un crecimiento en el número y variedad de las secciones. Los recitados y arietas predominaban entre los nuevos elementos, si bien otra secciones también eran significativas, sobre todo los graves y minués" (2000: 92). 
En conclusión, y como se intuye de lo expuesto hasta aquí, la Fábula de Polifemo y Galatea se presenta como paradigma del proceso de asimilación musical y poético-musical italiano adecuada a la dramaturgia palaciega española. Su naturaleza privada facilitó un tratamiento mucho más laxo de esas ceremonias lúdicas, lo que permitía la experimentación fuera de la obligada representativa oficial. Por ello, es un testimonio exquisito y muy a tener en cuenta del acercamiento poético-musical en el teatro hacia la moda europea -motivado por los cambios e influencias políticas y culturales- en la que la música tiene el protagonismo indiscutible. La imparable dinámica de innovación y renovación será promovida por personalidades como la reina Mariana de Neoburgo, el duque de Medinaceli o la condesa de Lemos, pero involucrará a dramaturgos y a compositores proclives para ello ${ }^{45}$. Así pues, antes de la llegada de los Borbones y de los gustos propios de Felipe V, de Madame de los Ursinos, y, muy especialmente, de Isabel de Farnesio, se inició una apertura que partía de la tradición como signo de identidad para engrandecerla a los parámetros culturales europeos. El resultado fue un diálogo operístico no uniforme, pero constante, que posibilitó la forja del discurso de la modernidad y una de las muestras más evidentes de resituar la cultura española dentro del nuevo tablero de ajedrez que era Europa a finales del siglo XVII y principios del siguiente.

\section{BiBLIOGRAFÍA}

ALONSO, Dámaso (2000). "La correlación en la estructura del teatro calderoniano". En Javier Aparicio Maydeu (ed.), Estudios sobre Calderón. Madrid: Istmo, vol. 1, pp. 290-350.

BANCES CANDAmo, Francisco (1970). Teatro de los teatros de los pasados y presentes siglos. Duncan W. Moir (ed.). London: Tamesis Books.

Baviera, Adalberto de, y Maura Gamazo, Gabriel (2004). Documentos inéditos referentes a las postrimerías de la Casa de Austria en España. Madrid: Real Academia de la Historia - Centro de estudios políticos y constitucionales.

\footnotetext{
${ }^{45}$ Con todo lo que ha proporcionado el estudio de la opereta Fábula de Polifemo y Galatea se consigue una especificación y mayor profundización en los jóvenes protagonistas que llevaron a cabo esos cambios en el teatro musical, el modo en que lo hicieron y los motivos que perseguían para ello, reafirmando lo expuesto por Stein (1993: 331). Del mismo modo, se ha pretendido colaborar con un granito de arena $-\mathrm{y}$ con resultado bastante positivo- en lo que reclamaba hace años Juan José Carreras: "una concepción renovada de la historiografía de la música teatral española debe pasar en mi opinión por una revisión del papel de lo italiano en la cultura musical del siglo XVIII" (1996: 51) .
} 
BECKER, Danièle (1989). "El teatro lírico en tiempo de Carlos II: comedia de música y zarzuela". En Javier Huerta Calvo, Harm den Boer, Fermín Sierra Martínez (eds.), El teatro español a fines del siglo XVII. Historia, cultura y teatro en la España de Carlos II. Amsterdam - Atlanta: Rodopi, vol. 2, pp. 409-434.

BERMEJo GREGORIO, Jordi (2017). “Quinto elemento es amor (1701): el fracaso de la representatividad de las fiestas reales del siglo XVII ante la nueva dinastía". En Blanca Ballester Morell, Antonio Bernat Vistarini y John T. Cull (eds.), Encrucijada de la palabra y la imagen simbólicas. Palma de Mallorca: José J. Olañeta - Universitat de les Illes Balears, pp. 91-105.

BERMEJO GREGORIO, Jordi (2019). "El hechizado por fuerza (1698) como proyecto social: sobre versiones hacia la modernidad", Dicenda. Cuadernos de Filología Hispánica (2019), vol. 38, pp. 75-98.

CALDERÓN DE LA BARCA, Pedro (1959). Obras completas. Tomo I. Dramas. Ángel Valbuena Briones (ed.). Madrid: Aguilar.

Calderón de la Barca, Pedro (1973). Obra completas. Tomo II. Comedias. Ángel Valbuena Briones (ed.). Madrid: Aguilar.

CALDERón DE LA BARCA, Pedro (2000). La fiera, el rayo y la piedra, en Obras Maestras. J. Alcalá-Zamora y J. M. Díez Borque (coords.). Madrid: Castalia España Nuevo Milenio.

CAÑIZARES, José de (2011). Acis y Galatea. María del Rosario Leal Bonmatí (ed.). Madrid: Iberoamericana-Vervuert - CSIC.

CARRERAS, Juan José (1995). "«Conducir a Madrid estos moldes». Producción, dramaturgia y recepción de la fiesta teatral Destinos vencen finezas (1698/99)", Revista de Musicología (1995), 18, 1/2, pp. 113-143.

CARRERAS, Juan José (1996). "Entre la zarzuela y la ópera de corte: representaciones cortesanas en el Buen Retiro entre 1720 y 1724". En Rainer Kleinertz (ed.), Teatro y música en España (siglo XVIII). Kassel Berlin: Reichenberger, pp. 49-77.

CARRERAS, Juan José (2000). "De Literes a Nebra: la música dramática entre la tradición y la modernidad". En Malcom Boyd y Juan José Carreras (eds.), La música en España en el siglo XVIII. Madrid: Cambridge University Press, pp. 19-28.

CARRERAS, Juan José (2004). "Ópera y dramaturgia en torno a 1700". En Juan José Carreras y Miguel Ángel Marín (eds.), Concierto barroco. Estudios sobre música, dramaturgia e historia cultural. Logroño, Universidad de La Rioja, pp. 23-28.

COTARELO Y MORI, Emilio (1917). Orígenes y establecimiento de la ópera en España hasta el 1800. Madrid: Tipografía de la Revista de Archivos, Bibliotecas y Museos.

DomínguEZ, José María (2009). "“Comedias armónicas a la usanza de Italia»: Alessandro Scarlatti's music and the Spanish nobility", Early Music (2009), XXXVII, 2, pp. 201-215.

DuRón, Sebastián (1696). Fiesta que se hizo a sus Mgdes. Se intitula Salir el amor del mundo (Biblioteca Nacional de España: M/2283).

DuRón, Sebastián (h. 1697), Muerte en amor es la ausencia: comedia en 3 jornadas / puesta en música por M. Durón. (Biblioteca Nacional de España: $\mathrm{M} / 1365)$. 
DuRÓN, Sebastián (2015). Selva encantada de amor. Raúl Angulo y Antoni Pons (eds.). Santo Domingo de la Calzada: Fundación Gustavo Bueno.

DuRón, Sebastián (2016). Coronis. Zarzuela. Raúl Angulo y Antoni Pons (eds.). Madrid: Ars Hispana.

DuRón, Sebastián (2017). Ópera deducida de la guerra de los gigantes. Raúl Angulo y Antoni Pons (eds.). Madrid: Ars Hispana.

DuRón, Sebastián, y Navas, Juan de (2017). Apolo y Dafne. Zarzuela. Raúl Angulo (ed.). Madrid: Ars Hispana.

FlóREZ AsEnsio, María Asunción (2006). Música teatral en el Madrid de los Austrias durante el Siglo de Oro. Madrid: ICCMU.

Gaceta de Madrid, 3, martes 21 de enero de 1698.

HILL, John Walter (2010). La música barroca. Música en Europa occidental, 1580-1750. Madrid: Akal.

JOSA, Lola, y LAMBEA, Mariano (2012). "Tonos humanos teatrales en el Cancionero Poético-Musical de Mallorca (CPMM) (finales del siglo XVIIprincipios del siglo XVIII)". En Patrizia Botta (coord.), Rumbos del hispanismo en el umbral del cincuentenario de la Asociación Internacional de Hispanistas. Roma: Bagatto Libri, vol. IV, pp. 143-151.

KLEINERTZ, Rainer (1996). "La zarzuela del siglo XVIII entre ópera y zarzuela. Dos aspectos de un género musical (1730-1750)". En Rainer Kleinertz (ed.), Teatro y música en España (siglo XVIII). Kassel - Berlin: Reichenberger, pp. 107-123.

Lanuza Mendoza y Arellano, Marcos de (1687). Las Belides. Madrid: Sebastián de Armendáriz.

LEZA, José Máximo (2004). " "Bellísimo Narciso» y músicas para seguir siéndolo. Transformaciones dramatúrgicas en el teatro español entre los siglos XVII y XVIII". En Juan José Carreras y Miguel Ángel Marín (eds.), Concierto barroco. Estudios sobre música, dramaturgia e historia cultural. Logroño: Universidad de La Rioja, pp. 47-76.

MARTín MARTínEZ, Rafael (2003). El teatro breve de Antonio de Zamora (estudio y edición), tesis doctoral. Madrid: Universidad Complutense de Madrid.

MARTín MoRENo, Antonio (1976). El padre Feijoo y las ideologías musicales del XVIII en España. Orense: Instituto de Estudios Orensianos.

MARTín MoREno, Antonio (1994). "El teatro musical en la Corte de Carlos II y Felipe V: Francisco Bances Candamo y Sebastián Durón”. En José Antonio Gómez Rodríguez y Beatriz Martínez del Fresno (eds.), F. Bances Candamo y el teatro musical de su tiempo (1662-1704). Oviedo: Ayuntamiento de Avilés - Universidad de Oviedo, pp. 95-155.

MARTínEZ LEIVA, Gloria (2013). "El exilio de la reina viuda Mariana de Neoburgo y la configuración de un nuevo retrato áulico". En Alfonso Rodríguez G. de Ceballos y Ángel Rodríguez Rebollo (coords.), Carlos II y el arte de su tiempo. Madrid: Fundación Universitaria Española, pp. 219-256.

MARTínEZ TORTAJADA, Sònia (2016). Contacto de lenguas y pueblos: el español y el alemán en la Austria de los siglos XVI y XVII. Kassel: Reichenberger.

NASARRE, Pablo (1724). Escuela música según la práctica moderna. Zaragoza: Herederos de Diego Larrumbe y Manuel Román, vol. I.

PÉREZ MAGALLÓn, Jesús (2002). Construir la modernidad: la cultura española en el tiempo de lo novatores (1675-1725). Madrid: CSIC. 
RodríGuez, Pablo-L. (2010). "Semblanzas de compositores españoles. Sebastián Durón (1660-1716)", Revista Fundación Juan March (2010), 391, pp. 2-7.

RussI, Francesco di (h. 1706). "Lunga stagione dolente". En Arie italiane di diversi autori escogidas para la Exma. A. Duquesa de Osuna, t. II, ff. 63r-66v (Biblioteca Nacional de España: M/2245).

SAGE, Jack (1970). "La música de Juan Hidalgo para Los celos hacen estrellas, de Juan Vélez de Guevara". En Juan Vélez de Guevara, Los celos hacen estrellas, J. E. Varey y N. D. Shergold (ed.), Jack Sage (ed. musical). London: Tamesis Books, pp. 169-223.

SANZ AYÁn, Carmen (2006). Pedagogía de reyes: el teatro palaciego en el reinado de Carlos II. Madrid: Real Academia de la Historia.

SOlAR-QUINTES, Nicolás Á. (1956). "Músicos de Mariana de Neoburgo y de la Real Capilla de Nápoles; facetas líricopalaciegas del último Austria y del primer Borbón", Anuario Musical (1956), XI, pp. 165-193.

StEIN, Louis K. (1993). Songs of Mortals, Dialogues of the Gods: Music and Theatre in Seventeenth-Century Spain. Oxford: Clarendon Press.

TORRENTE, Álvaro (2000). "Las secciones italianizantes de los villancicos de la Capilla Real, 1700-1740". En Malcom Boyd y Juan José Carreras (eds.), La música en España en el siglo XVIII. Madrid: Cambridge University Press, pp. 87-94.

UlLA LORENZO, Alejandra (2010). "Sobre el estreno de Muerte en amor es la ausencia de Antonio de Zamora. El testimonio de los embajadores toscanos", Theatralia: revista de poética de teatro (2010), 12, pp. 147-157.

ZAMORA, Antonio de ([1697]). Muerte en amor es la ausencia: comedia nueva (Biblioteca Nacional de España: MSS/15095).

Zamora, Antonio de ([1698]). Fábula de Polifemo y Galatea. [s. I.], [s. n.] (Biblioteca Nacional de España: T/546).

ZAMORA, Antonio de (1741). Obras cómicas de Antonio Vázquez de Zamora (Biblioteca Nacional de España: MSS/14771).

ZAMORA, Antonio de, y DURÓN, Sebastián (2012). Muerte en amor es la ausencia, Jordi Bermejo Gregorio (ed.), Lola Josa y Mariano Lambea (eds. musicales). Alicante: Biblioteca Virtual Miguel de Cervantes.

Fecha de recepción: 15 de febrero de 2020

Fecha de aceptación: 5 de mayo de 2020 